\title{
Blind spots in global soil biodiversity and ecosystem function research
}

\author{
Carlos A. Guerra (10) 1,2凶, Anna Heintz-Buschart (10) 1,3, Johannes Sikorski ${ }^{4}$, Antonis Chatzinotas (i) ${ }^{5,1}$, \\ Nathaly Guerrero-Ramírez ${ }^{1,6}$, Simone Cesarz ${ }^{1,6}$, Léa Beaumelle (1) 1,6, Matthias C. Rillig (1) 7,8, \\ Fernando T. Maestre (1D 9,10, Manuel Delgado-Baquerizo (1) 9, François Buscot (i) 3,1, Jörg Overmann (1) 4,11, \\ Guillaume Patoine ${ }^{1,6}$, Helen R. P. Phillips (1) 1,6, Marten Winter (1) 1,6, Tesfaye Wubet (1) 12,1, Kirsten Küsel (1) 1,13, \\ Richard D. Bardgett (10 ${ }^{14}$, Erin K. Cameron ${ }^{15}$, Don Cowan ${ }^{16}$, Tine Grebenc (D) ${ }^{17}$, César Marín (1) 18,19, \\ Alberto Orgiazzi (i) ${ }^{20}$, Brajesh K. Singh (D) 21,22, Diana H. Wall (1) ${ }^{23}$ \& Nico Eisenhauer (D) ${ }^{1,6}$
}

Soils harbor a substantial fraction of the world's biodiversity, contributing to many crucial ecosystem functions. It is thus essential to identify general macroecological patterns related to the distribution and functioning of soil organisms to support their conservation and consideration by governance. These macroecological analyses need to represent the diversity of environmental conditions that can be found worldwide. Here we identify and characterize existing environmental gaps in soil taxa and ecosystem functioning data across soil macroecological studies and 17,186 sampling sites across the globe. These data gaps include important spatial, environmental, taxonomic, and functional gaps, and an almost complete absence of temporally explicit data. We also identify the limitations of soil macroecological studies to explore general patterns in soil biodiversity-ecosystem functioning relationships, with only $0.3 \%$ of all sampling sites having both information about biodiversity and function, although with different taxonomic groups and functions at each site. Based on this information, we provide clear priorities to support and expand soil macroecological research.

\footnotetext{
${ }^{1}$ German Centre for Integrative Biodiversity Research (iDiv) Halle-Jena-Leipzig, Leipzig, Germany. ${ }^{2}$ Institute of Biology, Martin Luther University Halle Wittenberg, Am Kirchtor 1, 06108 Halle(Saale), Germany. ${ }^{3}$ Helmholtz Centre for Environmental Research - UFZ, Department of Soil Ecology, 06108 Halle (Saale), Germany. ${ }^{4}$ Leibniz-Institut DSMZ-Deutsche Sammlung von Mikroorganismen und Zellkulturen, Braunschweig, Germany. ${ }^{5}$ Helmholtz Centre for Environmental Research - UFZ, Department of Environmental Microbiology, Leipzig, Germany. ${ }^{6}$ Institute of Biology, Leipzig University, Leipzig, Germany. ${ }^{7}$ Freie Universität Berlin, Institut für Biologie, Altensteinstr. 6, 14195 Berlin, Germany. ${ }^{8}$ Berlin-Brandenburg Institute of Advanced Biodiversity Research (BBIB), Altensteinstr. 34, 14195 Berlin, Germany. ${ }^{9}$ Departamento de Biología y Geología, Física y Química Inorgánica, Escuela Superior de Ciencias Experimentales y Tecnología, Universidad Rey Juan Carlos, Calle Tulipán Sin Número, Móstoles 28933, Spain. ${ }^{10}$ Departamento de Ecología and Instituto Multidisciplinar para el Estudio del Medio "Ramón Margalef, Universidad de Alicante, Carretera de San Vicente del Raspeig s/n, 03690 San Vicente del Raspeig, Alicante, Spain. ${ }^{11}$ Microbiology, Braunschweig University of Technology, Braunschweig, Germany. ${ }^{12}$ Helmholtz Centre for Environmental Research UFZ, Department of Community Ecology, Braunschweig, Germany. ${ }^{13}$ Institute of Biodiversity, Friedrich Schiller University Jena, Dornburger-Straße 159, 07743 Jena, Germany. ${ }^{14}$ School of Earth and Environmental Sciences, The University of Manchester, Manchester M13 9PT, UK. ${ }^{15}$ Department of Environmental Science, Saint Mary's University, Halifax, NS, Canada. ${ }^{16}$ Centre for Microbial Ecology and Genomics, Department of Biochemistry, Genetics and Microbiology, University of Pretoria, Pretoria, South Africa. ${ }^{17}$ Slovenian Forestry Institute, Večna pot 2, SI-1000 Ljubljana, Slovenia. ${ }^{18}$ Instituto de Ciencias Agronómicas y Veterinarias, Universidad de O'Higgins, Rancagua, Chile. ${ }^{19}$ Instituto de Ciencias Ambientales y Evolutivas, Universidad Austral de Chile, Valdivia, Chile. ${ }^{20}$ European Commission, Joint Research Centre (JRC), Ispra, Italy. ${ }^{21}$ Hawkesbury Institute for the environment, Western Sydney University, Penrith, NSW 2751, Australia. ${ }^{22}$ Global Centre for Land-Based Innovation, Western Sydney University, Penrith, NSW 2751 , Australia. ${ }^{23}$ School of Global Environmental Sustainability and Department of Biology, Colorado State University, Fort Collins, CO 80523-1036, USA. ${ }^{凶}$ email: carlos.guerra@idiv.de
} 
S oils harbor a large portion of global biodiversity, including microorganisms (e.g., bacteria), micro- (e.g., Nematoda), meso- (e.g., Collembola), and macrofauna (e.g., Oligochaeta) ${ }^{1}$. This high biodiversity plays critical roles driving multiple ecosystem functions and services, including climate regulation, nutrient cycling, and food production ${ }^{1-6}$. Accordingly, recent experimental ${ }^{7,8}$ and observational ${ }^{9,10}$ studies, based either on particular biomes (e.g., drylands) or local sites, have shown that soil biodiversity is of high importance for the maintenance of multifunctionality (i.e. the ability of ecosystems to simultaneously provide multiple ecosystem functions and services ${ }^{11}$ ) in terrestrial ecosystems.

Nevertheless, and with few exceptions ${ }^{9,12}$, global soil biodiversityecosystem function relationships have not yet been studied in depth in macroecological perspectives and evaluations of patterns and causal mechanisms that link soil biodiversity to soil ecosystem functions have only emerged in the last decade $\mathrm{e}^{10,13-15}$. By comparison, albeit with important limitations ${ }^{16}$, there is a plethora of studies describing the global distribution and temporal patterns of aboveground biodiversity ${ }^{17}$, ecosystems ${ }^{18}$, and biodiversityecosystem function relationships ${ }^{12,19-23}$, something that is currently mostly absent (but see Delgado-Baquerizo et al. ${ }^{24}$ ) in soil macroecological studies due to the lack of temporally explicit data for soil biodiversity and soil-related functions.

Despite the mounting number of soil ecology studies, major gaps and/or geographic and taxonomic biases exist in our understanding of soil biodiversity ${ }^{25}$. Although the existing gaps in global soil biodiversity data are consistent with gaps in other aboveground biota $^{16,26,27}$, these are further exacerbated when described across specific ecological gradients (e.g., differences across altitudinal gradients) and taxa (e.g., Collembola, Oligochaeta) ${ }^{28}$. Furthermore, almost nothing is known about temporal patterns in soil biodiversity at larger spatial scales and across ecosystem types ${ }^{25}$. Identifying and filling these gaps on soil taxa distributions and functions is pivotal to identify the ecological preferences of multiple soil taxa, assess their vulnerabilities to global change, and understand the causal links between soil biodiversity, ecosystem functioning, and associated ecosystem services ${ }^{16,29}$. Despite growing scientific and political interest in soil biodiversity research ${ }^{25}$, little to no attention is given to the governance of soil ecosystems (Supplementary Fig. 1). This has resulted in a lack of inclusion of soil biodiversity and functions in land management and conservation debates, and environmental policy ${ }^{30}$.

In contrast to groups of organisms from other ecosystems (e.g., aboveground terrestrial ${ }^{31}$ ) for which the Global Biodiversity Information Facility (GBIF) constitutes already the main global data hub ${ }^{32,33}$, soil organisms are poorly represented. In fact, distribution data on soil taxa are spread across the literature, museum archives, and a number of non-interoperable platforms (e.g., EDAPHOBASE (https://portal.edaphobase.org/), the global Ants database ${ }^{34}$, the Earth Microbiome project ${ }^{35}$ ), and much needs to be done to fully aggregate these valuable resources. Across all available soil biodiversity data, major issues remain regarding their spatial and temporal representativeness (e.g., absent data in most tropical systems), and coverage of taxonomic groups (e.g., focus on fungi and bacteria), which limits our capacity to comprehensively assess and understand soil systems at multiple temporal and biogeographic scales. Also, even for the most represented taxa (i.e., bacteria and fungi), there are strong concerns regarding the current taxonomic depth ${ }^{36}$, even in better covered regions.

More importantly, both the lack of representativeness and the distribution of gaps in global soil biodiversity and ecosystem function research hampers the prioritization of future monitoring efforts $^{16}$. Such knowledge deficit in soil biodiversity also prevents stakeholders from taking appropriate management actions to preserve and maintain important ecosystem services ${ }^{37}$, such as food and water security, for which soils are the main provider ${ }^{1}$. Therefore, it is both timely and relevant to identify these blind spots in global soil macroecological knowledge and research. By doing so, we can assess their main causes and line up potential solutions to overcome them.

Since the mere accumulation of data will not advance ecological understanding ${ }^{38,39}$, it is important to identify how well the current macroecological studies cover the range of existing environmental conditions on Earth, including soil properties, climate, topography, and land cover characteristics ${ }^{40,41}$. Therefore, here we identify fundamental gaps in soil macroecological research by analyzing the distribution of sampling sites across a large range of soil organisms and ecosystem functions. In a review of current literature, we collected sample locations from most existing studies focused on soil macroecological patterns (see below; Table 2). The studies were then organized according to different soil taxonomic groups and ecosystem functions studied (nine and five categories, respectively, see Methods for more details). Finally, we examined how these macroecological studies have captured the diversity of global environmental conditions to identify critical ecological and geographical "blind spots" of global soil ecosystem research (e.g., specific land use types, soil properties, climate ranges; see Methods for more detail). By identifying the environmental conditions that have to be covered in future research and monitoring to draw an unbiased picture of the current state of global soils as well as to reliably forecast their futures, our synthesis goes a step beyond recent calls to close global data gaps ${ }^{25}$. Our comprehensive spatial analysis will help researchers to design future soil biodiversity and ecosystem function surveys, to support the mobilization of existing data, and to inform funding bodies about the allocation of research priorities in this important scientific field.

\section{Results and discussion}

Biogeographical biases. From our literature search, we collected details on locations of 17,186 individual locations/sampling sites representing macroecological studies on soil biodiversity $(N=$ $12,915)$ and ecosystem functions $(N=3318)$ (Fig. 1). In our assessment, we also included studies on soil organisms referring to organism biomass ( $N=977$; e.g. microbial and faunal biomass) as an important link between biodiversity and function, although our focus will be on the last two components. Bacteria, fungi, and soil respiration (Fig. 1a) were the best-represented soil taxa and functions in our literature survey, respectively. The total number of sites across all studies is low compared with many aboveground macroecological databases that surpass the numbers found here (e.g., the PREDICTS database ${ }^{42}$ contains $\sim 29,000$ sites across the globe).

Globally, soil biodiversity and ecosystem function data are not evenly distributed. Bacteria $(N=3453)$, fungi $(N=1687)$, and Formicoidea $(N=3024$; which together concentrate $48.8 \%$ of all soil biodiversity records) have comparatively large and geographically balanced distributions when compared to Rotifera $(N=$ $41)$, Collembola $(N=27)$, and Acari $(N=10)$, which have a substantially lower number of sampling sites and more scattered distributions (see Supplementary Fig. 2 for more detail). The distribution and availability of data for macroecological studies of soil organisms has changed dramatically during the last year, with the outcomes of efforts to synthesize local scale studies into largescale initiatives ${ }^{43,44}$. Thus, in the case of bacteria, fungi, Nematoda, and Oligochaeta (here including earthworms and enchytraeids), the relatively high number of sampling sites reflects a community effort to assemble databases based on collections from different projects ${ }^{10,45}$. In the case of Formicoidea, the availability of data reflects the outcome of systematic global 

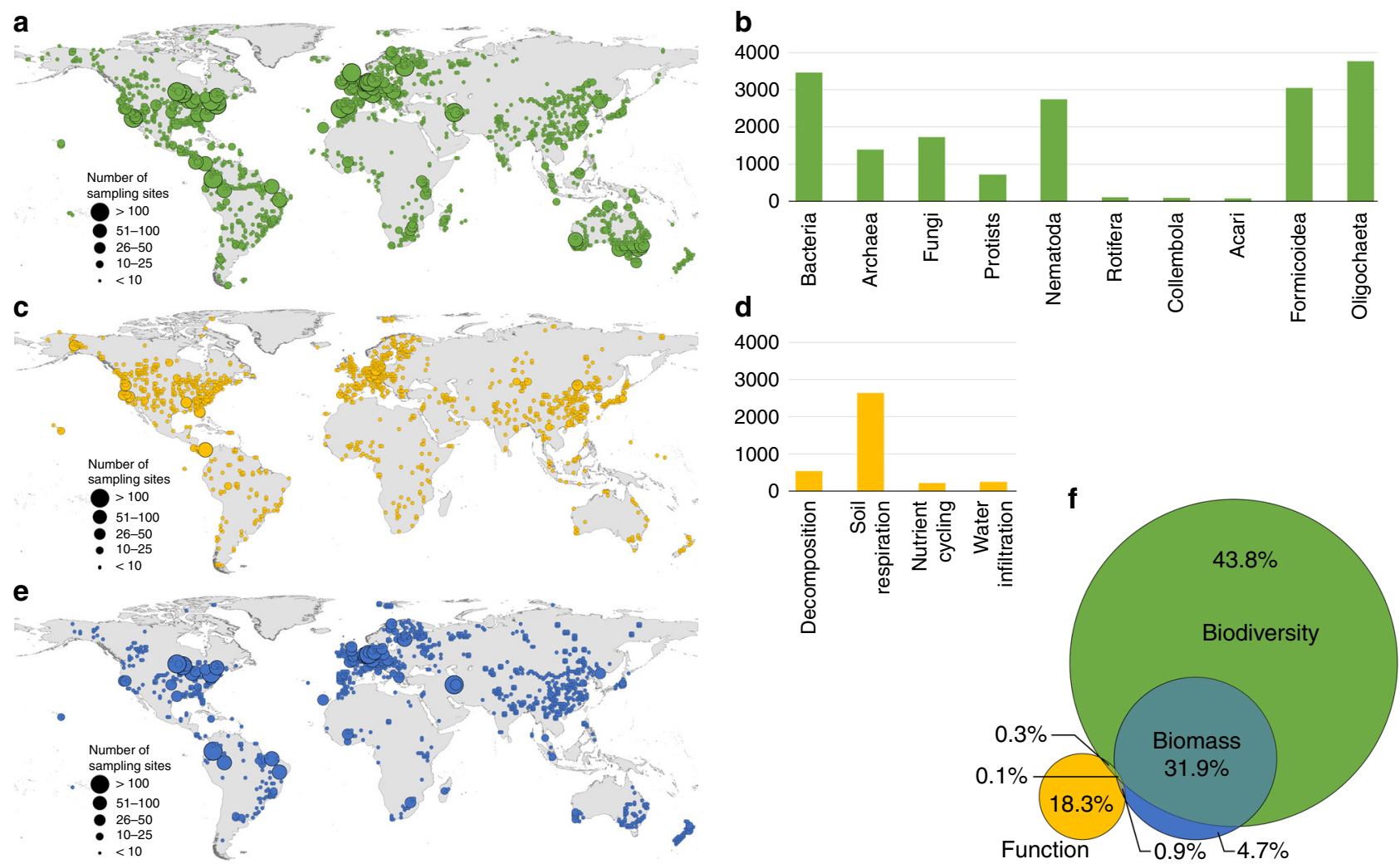

Fig. 1 Global distribution of sampling sites for soil taxa and soil ecosystem functions. $\mathbf{a}, \mathbf{b}$ correspond to the global number of individual sampling sites for each soil taxon, $\mathbf{c}, \mathbf{d}$ to the distribution of ecosystem functions, and $\mathbf{e}$ to the distribution of samples with biomass data. The venn diagram (f) indicates the proportion of sampling sites for soil taxa (in green), functions (in yellow), and biomass (in blue), and the $0.3 \%(N=63$ ) of overlap between biodiversity and function data points (this number does not mean that soil biodiversity and function were assessed in the same soil sample or during the same sampling campaign; i.e., there are thematic or temporal mismatches, see Supplementary Fig. 11 for more details), relative to the total number of sampling sites covered by the studies. The maps show the overall spatial distribution of sampling sites for all taxa (a) and soil ecosystem functions (c). The size of the circles corresponds to the number of sampling sites within a $1^{\circ}$ grid ranging from $<10$ to $>50$. All supporting data at: 10.6084/m9.figshare.12581306.

sampling initiatives ${ }^{46}$ or a combination of both ${ }^{47}$. Still, most of the analysis made so far lack a balanced representation of the world's ecosystems with most observations concentrated in temperate systems (Supplementary Fig. 4) and suffer from methodological limitations rising from the comparison of multiple methods and sampling schemes.

Soil ecosystems are by nature very heterogeneous at local scales $^{48}$. Having a small and scattered number of sampling sites for both soil functions and taxa (Supplementary Fig. 11) limits the power of current global analyses to evaluate macroecological relationships between soil biodiversity and ecosystem function, particularly for nutrient cycling and secondary productivity, which have strong local inter-dependencies ${ }^{49}$. In fact, from the five functions assessed here, there is a clear concentration of studies on soil respiration, accounting for $78.8 \%(N=2616)$ of all function records (Fig. 1d; see Supplementary Figure 3 for more detail).

We found a lack of matching data for soil biodiversity and multiple ecosystem functions in current global datasets. Due to the dependency of these and other soil functions on biodiversity ${ }^{2,50}$, being able to deepen our understanding of the strength and distribution of expected biodiversity and ecosystem function relationships is a needed step to better inform management and policy decisions ${ }^{51}$. In this context, only $0.3 \%$ of all sampling sites have an overlap between biodiversity and function datasets (corresponding to 67 sampling sites, Supplementary Fig. 11), with a non-systematic coverage of just a few taxa and functions across sites. Nowadays, macroecological studies on aboveground biodiversity and ecosystem functioning $19,42,52-55$ rely on data mobilization mechanisms that allow data to be reused to address multiple research questions. By contrast, apart from some taxonomic groups (i.e., bacteria and fungi) soil macroecological studies based on observational data have a very small degree of overlap and remain conditioned by poor data sharing and mobilization mechanisms ${ }^{56-58}$. Two exceptions to the latter are recent studies on nematodes ${ }^{44}$ and earthworms ${ }^{43}$ that relied on large synthesis of locally available data, paving the way for more efforts in synthesizing soil diversity data. Nevertheless, these studies have to cope with large arrays of methodological approaches that limit some macroecological analysis (e.g., compositional turnover studies). Also, although the large number of sampling locations, these new datasets further reflect the current biases in macroecological findings by being skewed toward temperate systems (Supplementary Fig. 12).

We also found that most studies are based on single sampling events, i.e., without repeated measurements over multiple years or long time periods for the same sampling sites. Being able to study how communities and functions change over time is essential for assessing trends in key taxa and functions, and their vulnerability to global change ${ }^{17}$. Our global survey suggests that such information is almost nonexistent in large-scale soil biodiversity and ecosystem functions studies. Thus, for most soil communities and functions, although local studies exist ${ }^{59,60}$, understanding the global trends and the implications of global change drivers and scenarios is difficult and limited by the absence of globally distributed and temporally explicit observational data. 
Ecological blind spots. Overall, both soil biodiversity and ecosystem function variables reveal a high degree of spatial clustering across global biomes: temperate biomes (especially broadleaved mixed forests and Mediterranean) contain more sampling sites than tundra, flooded grasslands and savannas, mangroves, and most of the tropical biomes, with the exception of moist broadleaf forests (Supplementary Fig. 4). This spatial clustering is even more pronounced in studies of ecosystem functions, with temperate systems being overrepresented with $62 \%$ of all sampling sites, while the rest of the globe has scattered information on soil conditions. This likely reflects differences in funding availability and research expertize across countries ${ }^{27,61}$. In fact, for taxa like Collembola and Nematoda (despite a large number of sampling sites), most sampling sites are concentrated in temperate regions, with very few documented in other regions. This imbalance results in quite accurate predictions of soil biodiversity for temperate regions, but with high standard errors elsewhere, which is further enhanced when coupled with non-spatially-stratified algorithms ${ }^{43,44,62}$.

Furthermore, the availability of soil biodiversity and function data is especially scarce or even non-existent in tropical and subtropical regions (see Supplementary Fig. 4 for more details), which are among the most megadiverse places on Earth, montane grasslands, and hyper-arid areas. In many cases, local experts and study sites may exist, although their contributions are often not included in macroecological studies and therefore their environmental characteristics are not covered. At the same time, for many of the best-represented regions in the globe, there is rarely a complete coverage of soil taxa and functions, with records often being dominated by one or two densely sampled taxa (e.g., bacteria and fungi) or functions (e.g., soil respiration).

The range of environmental conditions currently described within soil macroecological studies is necessary to understand the relationship between soil biodiversity, ecosystem functions, and key environmental conditions (e.g., the known relationship between bacteria richness and $\mathrm{pH}^{62}$ or the dependence of soil respiration on temperature $\left.{ }^{63,64}\right)$. In this context, the complete range of soil carbon levels existing on Earth is not well covered, with soils of very high and low carbon contents (Fig. 2a) being underrepresented compared with their global distribution. The same applies to soil type, with only a fraction of soil types being well covered (i.e., acrisols, andosols, cambisols, kastanozems, luvisols, and podzols), while others are underrepresented or completely absent (e.g., durisols, stagnosols, and umbrisols; Fig. 2o). In contrast, our study identified over- and underrepresented environmental conditions in soil biodiversity and function studies (Fig. 2). For example, some soil properties are well represented across studies, such as soil texture (i.e., sand, silt, and clay content) and $\mathrm{pH}$, with the exception of extreme ranges (e.g., $\mathrm{pH}>7.33$ or silt content $<19 \%$ ).

In contrast to soil conditions, climate variability is poorly covered in soil biodiversity and function studies, with several climatic ranges being almost completely missing (Fig. 2f-k). These include low and high potential evaporation/aridity areas and those with high climate seasonality, low precipitation, and extreme temperatures (i.e., very hot and very cold systems), with no overall differences in coverage between biodiversity and ecosystem function studies. Drylands, for example, cover $45 \%$ of the land surface 65 and have been shown to be highly diverse in terms of soil biodiversity and with strong links to specific ecosystem functions ${ }^{24,66}$, but are often underrepresented (although some studies specifically target them ${ }^{10,12}$ ). Climatic conditions (current and future) have strong influences on both soil organisms $s^{60}$ and functions $s^{63,67,68}$. As such, assessing a wide range of these conditions, including climatic extremes, is fundamental to describe the complex dynamics of soil systems. This issue is further exacerbated when looking at specific climate combinations (Fig. 3c), where $59.6 \%$ of the global climate conditions are not covered by any of the studies considered.

Although representing a major driver of soil biodiversity and function ${ }^{4}$, land-cover based studies have shown different responses across groups of soil organisms $s^{59,69,70}$ and specific functions ${ }^{71,72}$. While, in general, land cover types are well covered, sites in the proximity of urban areas are disproportionately overrepresented (Fig. 2n). Climate and soil properties shape soil communities worldwide ${ }^{62}$. Nevertheless, anthropogenic disturbances, particularly those related to land-use change and intensity, have important impacts on these soil communities and their functional performance. Lichens, mosses, and bare areas have been neglected, and shrublands are not well represented in ecosystem function assessments. These gaps may have important implications, particularly when they correlate with understudied ecosystems like drylands or higher latitude systems that may harbor high biodiversity ${ }^{66}$, but for which patterns are mostly unknown. In this context, the present analysis indicates that low diversity areas (here represented as plant richness ${ }^{73}$ ) are absent from most studies or poorly represented, with the focus being mostly on higher diversity areas. Concurrently, it has been suggested that there may be important mismatches between above- and belowground biodiversity across the globe ${ }^{74}$, i.e., there are huge areas where aboveground biodiversity does not well predict belowground biodiversity. Although most macroecological studies point in this direction (mismatch between above- and belowground diversity), there are still important dependencies between above- and belowground diversity ${ }^{75,76}$. These dependencies can be functional and, in the case of some groups (e.g., like fungi), can also increase diversity and biomass, with positive effects on soil carbon storage ${ }^{77}$.

When looking at how belowground studies cover global environmental conditions (Fig. 3a, c), important spatial gaps are observed. Although most soil-related variables are well covered across studies, the same does not apply when looking at aboveground diversity (see Supplementary Fig. 10), which shows a very good coverage in forest and crop areas with aboveaverage plant richness in mid to low elevations, while other environmental combinations are underrepresented. Overall, while it is unreasonable to expect all macroecological studies to cover all possible soil conditions our results show that most studies have, on average, a coverage below $50 \%$ across global regions, with the exception of Central and west Europe and Caribbean (for both biodiversity and function) and Central and North-East Asia and North and South America (for ecosystem functions). All other regions show a systematic poor coverage across soil macroecological studies with North Africa and West Asia having the lowest average environmental coverage (Fig. 3b, d).

Although temperate regions (e.g., Central and West Europe) have the highest average environmental coverage across soil macroecological studies, within these regions many environmental combinations are not properly covered, particularly areas of high altitude with low $\mathrm{pH}$ and high carbon content (see Fig. 3AF, BF). Worryingly, regions or countries considered to be megadiverse (i.e., at least from an aboveground diversity point of view) are systematically poorly represented across soil macroecological studies (Fig. $3 \mathrm{aB}, \mathrm{aE}, \mathrm{aD}, \mathrm{cB}, \mathrm{cE}, \mathrm{cD}$ ).

Many of the reasons and drivers of existing data gaps have already been discussed in recent literature for aboveground systems $^{16}$ (e.g., accessibility, proximity to large cities, etc.). In the case of soil biodiversity and ecosystem functions, these blind spots are further reinforced because of the lack of standardized protocols for acquiring biodiversity and ecosystem function data. This translates into an absence of comparable data, which is even 

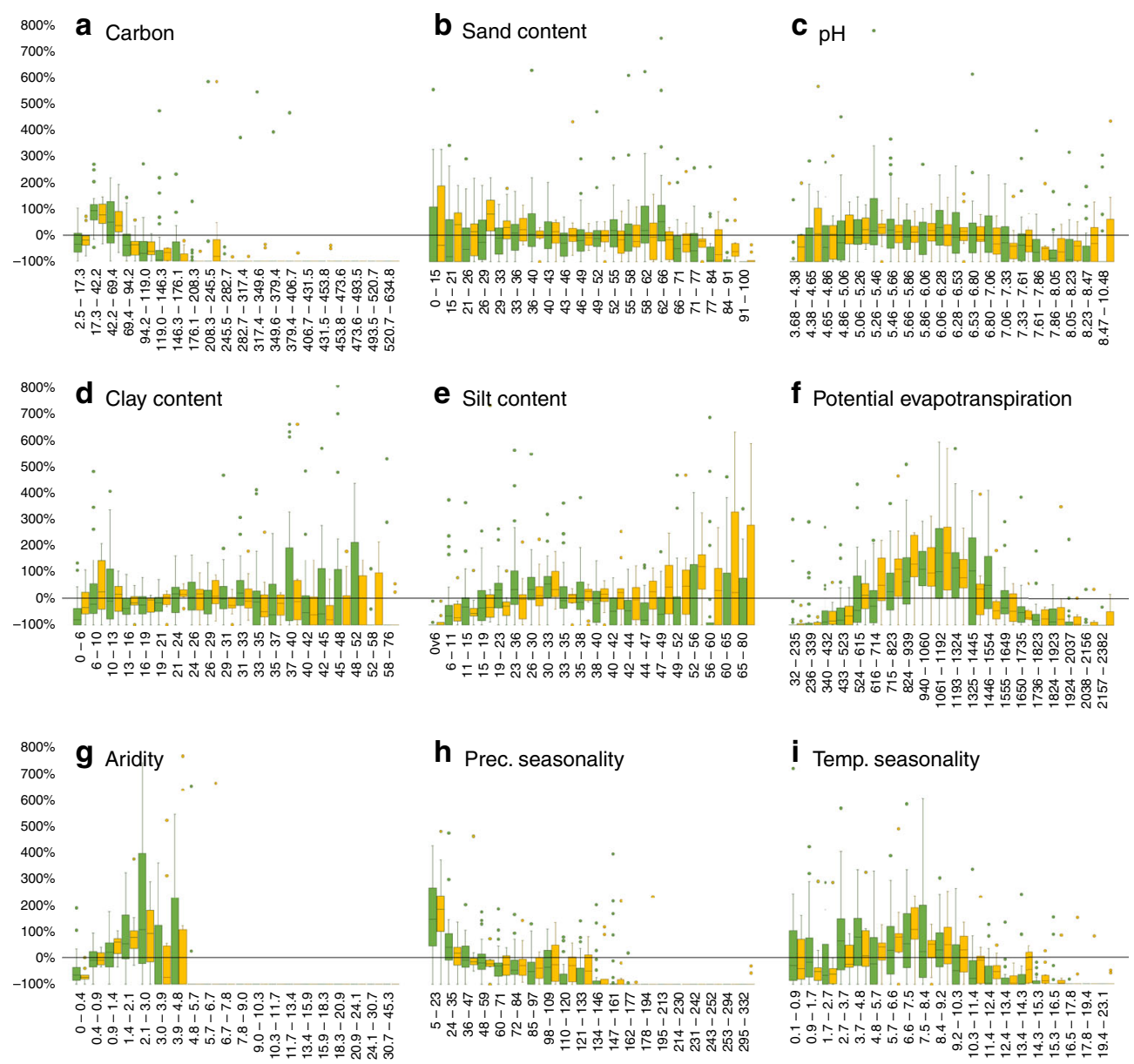

h Prec. seasonality

i Temp. seasonality
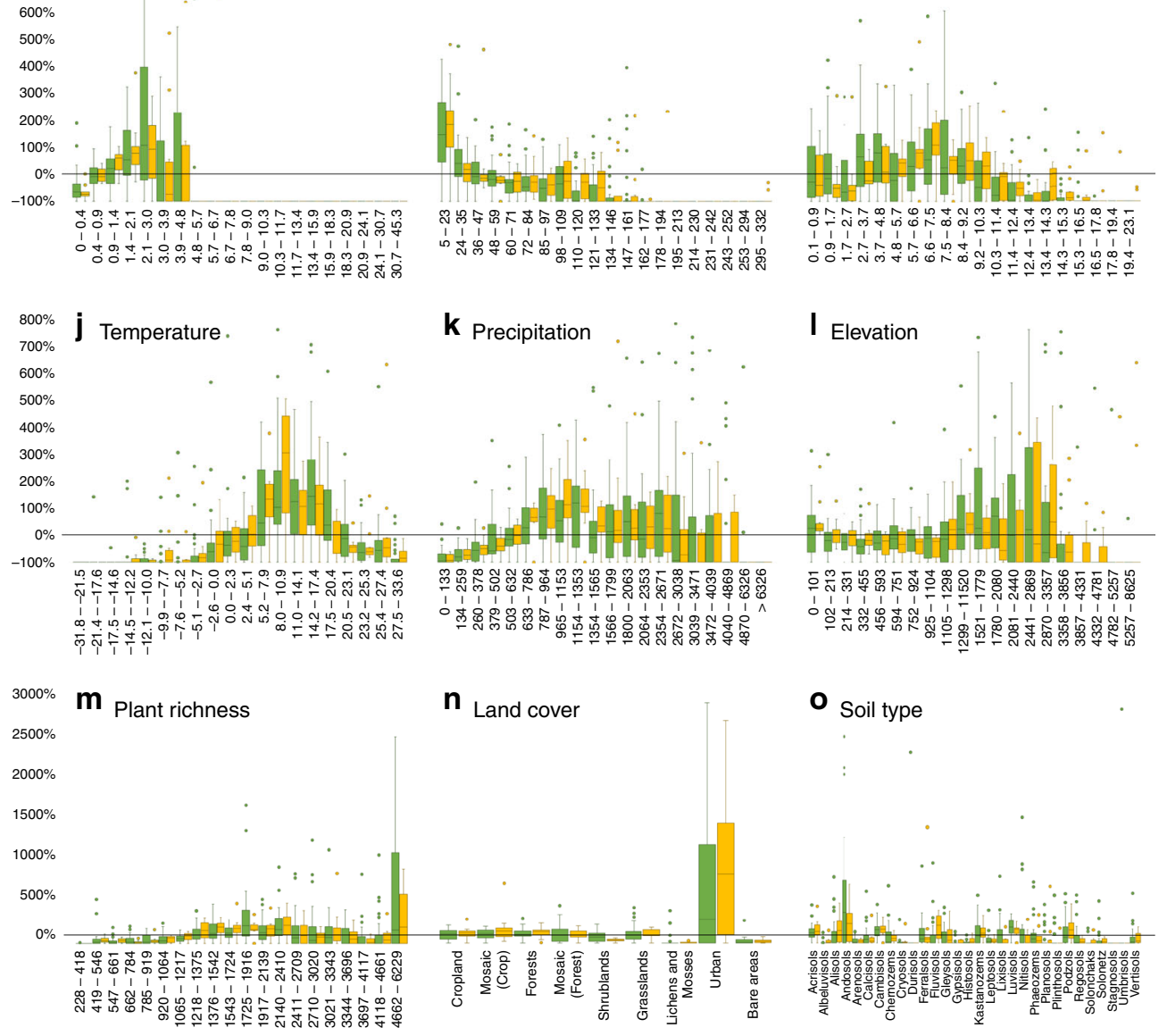

more pronounced than in other systems ${ }^{16,78}$. Nevertheless, there is a continuous movement towards improving data mobilization and international collaborations that could help overcome these issues if steered in the direction of underestimated taxa and/or functions identified here ${ }^{79}$.

In a changing world where soil biodiversity shifts are being systematically reported ${ }^{80-82}$, and where current forecasts are pointing to increases in land-use intensity ${ }^{83,84}$, desertification ${ }^{85}$, and rapid climate change ${ }^{86-89}$, understanding if and to what extent biodiversity changes are happening in soil communities is of high importance. This is particularly relevant to assess causal effects between changes in biodiversity and ecosystem function (e.g., are changes in biodiversity occurring because of changes in function, paired with them, or despite them, and vice versa), which is even more relevant if key ecosystem functions (e.g., carbon sequestration) are the subject of evaluation. 
Fig. 2 Global soil ecological blind spots. Values ( $y$-axis) correspond to the percentage of sites per study when compared with the global percentage distribution (e.g., a value of $20 \%$ means that a given study overrepresents a given environmental variable by $20 \%$, when compared to the global distribution of that same variable). Soil biodiversity studies in green $(N=35)$ and ecosystem function studies in orange $(N=12)$. a soil carbon $\left(g\right.$ soil kg $\left.{ }^{-1}\right)$ 127; b sand content $(\%)^{127}$; c soil $\mathrm{pH}^{127}$; d clay content $(\%)^{127}$; e silt content $(\%)^{127} ; \mathbf{f}$ potential evapotranspiration (mm/day) ${ }^{128} ; \mathbf{g}$ aridity index ${ }^{128} ;(\mathbf{h})$ precipitation seasonality ${ }^{129} ;$ (i) temperature seasonality ${ }^{129} ; \mathbf{j}$ mean annual temperature $\left({ }^{\circ} \mathrm{C}\right)^{129} ; \mathbf{k}$ mean total precipitation $(\mathrm{mm})^{129} ; \mathbf{I}$ elevation $(\text { meters })^{130}$; $\mathbf{m}$ vascular plant richness ${ }^{73} ; \mathbf{n}$ land cover $^{131}$; and $\mathbf{o}$ soil type ${ }^{127}$. The zero black line corresponds to a situation where the proportion of sites in a given class within a study matches the global proportional representation of the same class. Although outliers were not eliminated, for representation purposes these were omitted $>800 \%$ between panels $\mathbf{a}-\mathbf{I}$ and $>3000 \%$ for panels $\mathbf{m}-\mathbf{0}$. The class intervals of each continuous variable were obtained based on a natural breaks (Jenks) classification (20 classes). Each barplot (quantile distribution) represents the proportional number of sampling sites covering a particular class when compared to the global distribution. In panel (n) mosaic (crops) represent small scale landscapes dominated by crops, while mosaic (forests) represent small scale landscapes dominated by forests.
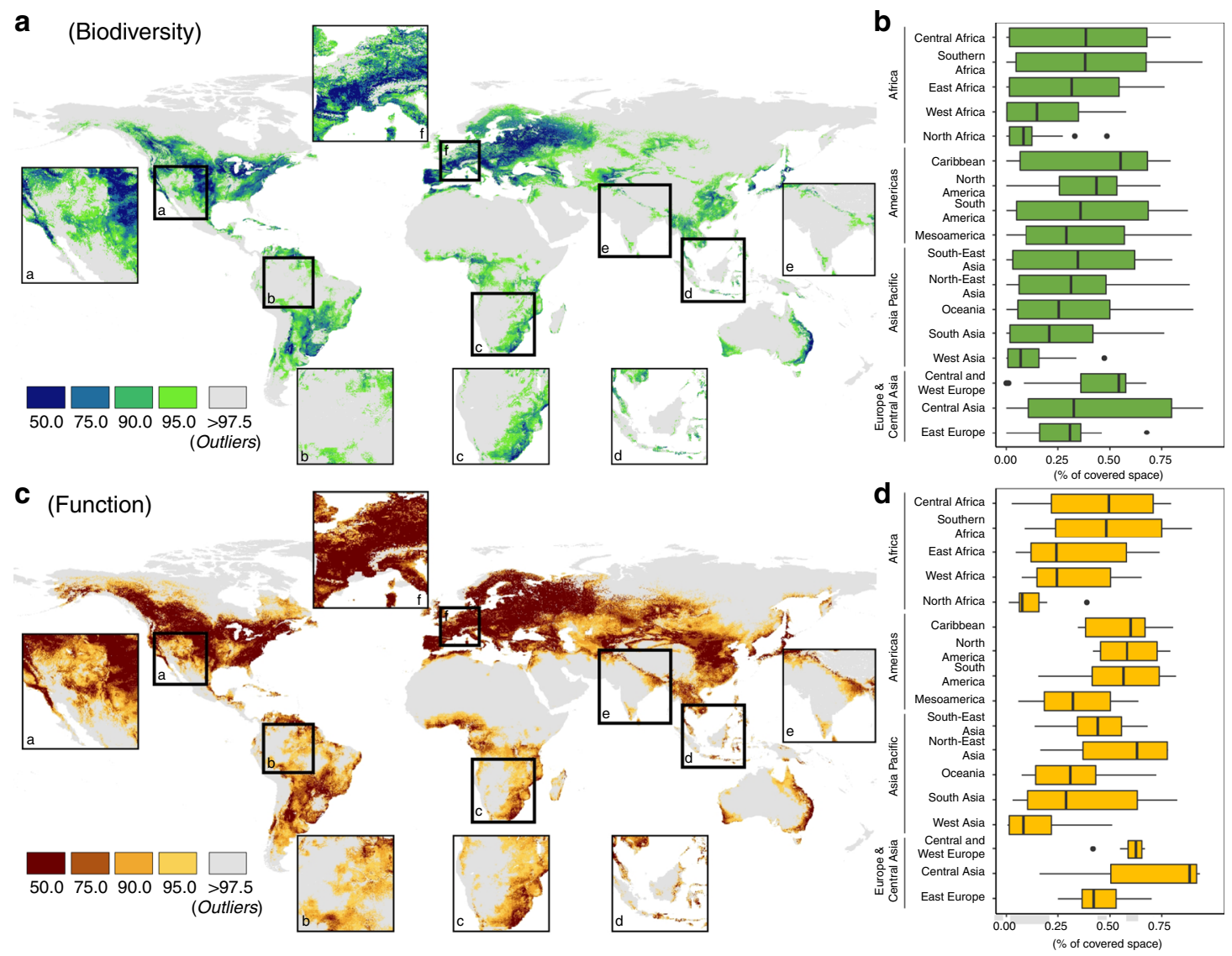

Fig. 3 The extent to which main soil environmental characteristics are covered across macroecological studies. Colors (in a and c) correspond to the average $\chi^{2}$ values across all studies considered and environmental conditions calculated based on Mahalanobis distance ${ }^{123-125}$ (gray color corresponds to outlier conditions: see Methods for more details) within: $\mathbf{a}$ and $\mathbf{b}$ corresponding to the biodiversity studies and $\mathbf{c}$ and $\mathbf{d}$ to ecosystem function studies. $\mathbf{a}$ and c correspond to the spatial distribution of the $\chi^{2}$ values to $0.50,0.75,0.90,0.95$, and 0.975 break points. b and c correspond to boxplots (quantile distribution) of the percentage of area covered $\left(<0.975 \chi^{2}\right)$ by each study considered across the different IPBES regions. Results show that most studies have, on average, a coverage below $50 \%$ of all the regions in the world, with the exception of Central and west Europe (f) and Caribbean (for both biodiversity and function), Central and North-East Asia, and North and South America (for ecosystem functions). a-f correspond to zooms on specific areas of the globe. All supporting data at: 10.6084/m9.figshare.12581306.

Challenges to move beyond blind spots. Filling the knowledge gap on large-scale temporal trends in soil biodiversity and ecosystem function cannot be achieved without spatially explicit studies based on resampled locations. This could be done with a standardized global monitoring framework that is recognized and supported by a large number of countries, which currently does not exist. Given the strength of recognized soil taxa interactions ${ }^{90}$, biodiversity and ecosystem function relationships ${ }^{24}$, and abovebelowground interactions ${ }^{91}$, these large-scale monitoring activities and research studies should consider going beyond traditional single taxa/function approaches and collect information on the multiple dimensions of soil ecosystems ${ }^{28}$, while at the same time expanding/supporting surveys to cover the blind spots of soil macroecological research (Fig. 3).

Across all soil taxa and functions, the geographical and ecological blind spots identified here often emerge from a number of obstacles specific to soil ecology ${ }^{79}$ (see summary in Table 1). Soil macroecologists face many challenges and constraints spanning from a lack of methodological standards and scientific expertize in different taxonomic groups ${ }^{92-94}$, to limitations caused by the current implementation of the Convention for Biological Diversity (CBD) and the Nagoya Protocol ${ }^{95,96}$. While 
Table 1 Summary of the main obstacles soil ecologists face to create a global soil biodiversity monitoring network and the priority actions to overcome them.

\begin{tabular}{|c|c|c|c|}
\hline Challenges & $\begin{array}{l}\text { Researchers } \\
\text { Priority actions }\end{array}$ & Institutions & Policymakers \\
\hline $\begin{array}{l}\text { Legal issues regarding the } \\
\text { transport and sharing of soil } \\
\text { samples and biological data }\end{array}$ & $\begin{array}{l}\text { Raise the awareness of institutions } \\
\text { and decision-makers about the } \\
\text { importance of these legal bottlenecks } \\
\text { for the development of international } \\
\text { research programs. }\end{array}$ & $\begin{array}{l}\text { Develop a legal understanding of the } \\
\text { implications of material transfer } \\
\text { mechanisms for soil samples and provide } \\
\text { support to researchers also by promoting } \\
\text { knowledge and expertize exchange. } \\
\text { Support and facilitate the establishment } \\
\text { of international consortia and bilateral } \\
\text { institutional agreements particularly with } \\
\text { developing countries }\end{array}$ & $\begin{array}{l}\text { Establish global multilateral } \\
\text { solutions and International Treaties } \\
\text { focused on soil biodiversity and } \\
\text { ecosystem function research. } \\
\text { Establish knowledge transfer } \\
\text { mechanisms for soil-related research } \\
\text { together with the classification of } \\
\text { soil samples for research purposes. }\end{array}$ \\
\hline $\begin{array}{l}\text { Scattered literature and lack } \\
\text { of mobilization/ } \\
\text { systematization of local } \\
\text { studies }\end{array}$ & $\begin{array}{l}\text { Invest in data harmonization, } \\
\text { synthesis, meta-analysis approaches, } \\
\text { data collation, and standardizedr } \\
\text { metadata to improve currently } \\
\text { available datasets (e.g., through GBIF } \\
\text { for soil biodiversity). } \\
\text { Publishing under free "Open Access" } \\
\text { (OA) licence and/or using preprint } \\
\text { platforms or fully OA journals. } \\
\text { Define and publish data standards } \\
\text { that allow for better data transfer } \\
\text { focussing on the methods, reporting } \\
\text { in standard units, and best practices } \\
\text { for data availability. } \\
\text { Increase the focus on understudied } \\
\text { soil groups (e.g., collembola, acari, } \\
\text { protists, mammals) and functions } \\
\text { (e.g., soil aggregate stability, } \\
\text { bioturbation, nutrient cycling). } \\
\text { Establish effective coordination of } \\
\text { current networks to support the } \\
\text { development of integrated ecological } \\
\text { assessments of the soil realm }\end{array}$ & $\begin{array}{l}\text { Adoption of available data and methods } \\
\text { standards } 101,132-136 \text { and support the } \\
\text { establishment and maintenance of data } \\
\text { repositories and open access policies. }\end{array}$ & $\begin{array}{l}\text { Support open access partnerships } \\
\text { (e.g., the German DEAL }{ }^{137} \text { ) to } \\
\text { facilitate knowledge transfer and } \\
\text { collaboration across countries and } \\
\text { researchers from different } \\
\text { backgrounds and expertize. } \\
\text { Improve the digitally available data } \\
\text { on soil biodiversity and ecosystem } \\
\text { function by supporting the } \\
\text { expansion of current global } \\
\text { databases (e.g., GBIF) or the } \\
\text { creation of interoperable data } \\
\text { infrastructures on soil function data. }\end{array}$ \\
\hline $\begin{array}{l}\text { Lack of temporally explicit } \\
\text { information on soil } \\
\text { biodiversity and functions }\end{array}$ & $\begin{array}{l}\text { Identify relevant sites - e.g., sites } \\
\text { covering a wide range of taxa or } \\
\text { functions and/or a high degree of } \\
\text { standardization - for resampling. } \\
\text { Revisit already sampled sites to } \\
\text { obtain temporal measurements of } \\
\text { soil biodiversity and ecosystem } \\
\text { function. }\end{array}$ & $\begin{array}{l}\text { Institutional support of long-term } \\
\text { databases and collections of soils, soil } \\
\text { functional data, and soil biological } \\
\text { material. }\end{array}$ & $\begin{array}{l}\text { Create funding schemes for strategic } \\
\text { long-term research projects on soil } \\
\text { monitoring and research (e.g., using } \\
\text { the LTER framework as an } \\
\text { example }{ }^{138} \text { ). }\end{array}$ \\
\hline $\begin{array}{l}\text { Lack of globally distributed } \\
\text { expertize, research funding } \\
\text { and infrastructures }\end{array}$ & $\begin{array}{l}\text { Promote knowledge transfer } \\
\text { mechanisms and capacity building, } \\
\text { especially with developed countries } \\
\text { that might see little advantage of } \\
\text { being involved in a global network } \\
\text { that only offer co-authorship as the } \\
\text { main benefit. } \\
\text { Setup international workshops, } \\
\text { summer schools, or classes with a } \\
\text { focus on educating the next } \\
\text { generation of scientists on different } \\
\text { aspects of soil ecology. }\end{array}$ & $\begin{array}{l}\text { Build on or expand current networks to } \\
\text { include knowledge transfer activities, } \\
\text { namely on education, methods } \\
\text { calibration, sharing research facilities, } \\
\text { and taxonomic expertize. }\end{array}$ & $\begin{array}{l}\text { Promote funding flexibility to train } \\
\text { and empower researchers across } \\
\text { countries and/or regions, also } \\
\text { allowing local scientists, particularly } \\
\text { in the developing world, to conduct } \\
\text { soil biodiversity and ecosystem } \\
\text { function research. } \\
\text { Establish soil health as a research } \\
\text { priority beyond farming areas and } \\
\text { with a special focus on ecological } \\
\text { conservation of soil organisms and } \\
\text { ecosystem functions. }\end{array}$ \\
\hline
\end{tabular}

the first has more immediate, albeit non-trivial solutions (e.g., by expanding the language pool of the researchers and studies included ${ }^{16,97}$ and by applying common standards for sampling, extraction, and molecular protocols ${ }^{98-101}$ ), the latter contains systemic issues that go beyond soil ecology alone. In this context, although the CBD and the Nagoya Protocol were created to protect countries while making the transfer of biological material more agile, numerous states have either not yet implemented effective national "Access and Benefit Sharing" (ABS) laws or have implemented very strict regulations ${ }^{102,103}$. Yet, even after 25 years of the $\mathrm{CBD}$ and the ABS framework being in place, the major motivation for a strict national regulation - the anticipated commercial benefits and high royalties from the "green gold" has not yet materialized ${ }^{95,104}$.

Researchers have yet to coordinate a global effort to characterize the multiple aspects of soil biodiversity and function in a comprehensive manner, with the current literature dominated by scattered, mostly local studies focused on specific soil organisms and/or functions. Although here we do not comprehensively assess the potential of local studies to overcome the current blind spots, 
other studies $34,35,67$ have shown that, with an effort in standardization and data mobilization, local and regional studies add fundamental knowledge and empower local researchers to participate in global initiatives. In fact, several studies not included in this assessment can provide a finer-scale resolution in many areas of the globe ${ }^{69,105,106}$. Nevertheless, their spatial extent systematically coincides with overrepresented areas (e.g., temperate areas), and their taxonomic and functional focus is mostly on the already prevailing taxa (i.e., bacteria and fungi) and functions (i.e., soil respiration), potentially increasing existing biases. This increases the relevance of facilitating data mobilization from regions and, more importantly, environmental conditions that are systematically not covered by macroecological studies. Here a word of caution is needed as scientists from around the world need to publish their findings to progress their careers and/or to obtain research funding. Managing large data sets and having access to global databases on climatic and soil information, is often a privilege for well-resourced research teams (in terms of bibliographic subscriptions, computing power and technical knowledge, and software $\left.{ }^{107,108}\right)$. Given the diversity of global conditions (both scientific and environmental), data mobilization alone is not the solution and needs to be paired with the priority to have more national (and local) surveys across a large number of sites and with a deeper taxonomic level.

In parallel, and given the nature of global change drivers, understanding their influence on local soil communities and ecosystem functioning requires global macroecological approaches that can provide context, predictions, and concrete suggestions to policymakers across the globe. Yet these macroecological approaches will be less effective in providing relevant outputs at national scales if based on data extrapolated from other countries; they would be strongly improved if local data would exist coming from national and local surveys and were made openly available 25,109 . Without more comprehensive studies seeking answers to large-scale soil ecological questions - often involving dealing with multiple scales (temporal and spatial) and a number of thematic and taxonomic depths ${ }^{74}$ - it is difficult to deepen soil macroecological knowledge ${ }^{110}$. This is particularly relevant in testing biodiversity and ecosystem function relationships at the global scale, or trying to address specific societal issues (e.g., the attribution of climate and land-use change as drivers of soil ecological change or general biodiversity trends) ${ }^{17}$.

Another major challenge is associated with the fact that currently ABS agreements are bilateral. This hinders global soil ecology initiatives, as it requires that providers and receivers need limited (in time and topic) individual material transfer agreements. Thus, for a global initiative, this can amount to hundreds of material transfer agreements. However, there is an increasing quest for global solutions and multilateral systems, such as the International Treaty on Plant Genetic Resources for Food and Agriculture (IT PGRFA; www.fao.org/3/a-i0510e.pdf), or other harmonized best practices examples like the Global Genome Biodiversity Network ${ }^{96}$. As the commercial value of soil organisms is regarded to be zero in situ ${ }^{111}$, and as these are mostly ubiquitously distributed at the highest taxonomic level (e.g., bacteria and fungi), soil per se has no commercial value as it does not match the criteria that "provider countries host unique and unmatched biodiversity" of the Nagoya Protocol ${ }^{112}$. Therefore, a global multilateral solution, similar to the examples listed above (e.g., the IT PGRFA), but focused on facilitating the exchange of soil samples to drive basic research on soil biodiversity, taxonomy, and ecosystem functioning, while still safeguarding against the spread of foreign genotypes, is pressingly needed. At the same time, as long as bilateral ABS agreements are required, researchers should engage with local policymakers to enable unrestricted soil biodiversity and ecosystem function research, as was the case for Brazil from 2006 to $2016^{113}$.
Looking for solutions to unearth global observations. Globally, soil habitats are under constant pressure from major threats, such as climate change, land use change and intensification, desertification, and increased levels of pollution. Here, we argue for global monitoring initiatives that systematically samples soil biodiversity and ecosystem functions across space and time. Such global initiatives are urgently needed to fully understand the consequences of ongoing global environmental change on the multiple ecosystem processes and services supported by soil organisms (Table 1). This requires that current and future funding mechanisms include higher flexibility for the involvement of local partners from different countries in global research projects. Given that soil ecological research requires cross-border initiatives ${ }^{79,108}$ and often expensive laboratory infrastructure, there is a need for flexible funding with proper knowledge transfer mechanisms to sustain global soil macroecological research. Such knowledge will in turn contribute to advancing our understanding of macroecological patterns of soil biodiversity and ecosystem function, thereby fulfilling national and global conservation goals ${ }^{11,114,115}$.

Considering the current pool of literature, improving the digitally available data on soil biodiversity and ecosystem function should be a top priority that can be supported by systematically mobilizing the underlying data ${ }^{116}$ in already existing open access platforms (e.g., GBIF). Achieving this goal on shared knowledge and open access data will return benefits beyond making global soil biodiversity surveys possible. It will allow local researchers to expand their own initiatives, create a more connected global community of soil ecologists, bypassing publication and language limitations, and potentially open doors in countries that may otherwise be reluctant in sharing their soil biodiversity data ${ }^{27}$.

In parallel, coordinated sampling strategies based on standardized data collection and analysis are needed to improve soil macroecological assessments. From our results, it is clear that most, if not all, studies look at only a fraction of the soil realm without much spatial and thematic complementarity of global environmental conditions. Also, the small overlap between biodiversity and functional studies indicates that most community assessments disregard the ecosystem functions that these provide and vice versa, prompting a call for more complex approaches that can show potential links and global ecosystem services. Our study helps to identify global target locations and biomes, which need to be given priority in future surveys. Future sampling strategies would greatly benefit from coordinated sampling campaigns with biodiversity and function assessments at the same locations and ideally from the same soil samples to improve the current spatial-temporal resolution of data on soil biodiversity and ecosystem functions.

These two complementary pathways (i.e., data mobilization and sharing of current literature and a globally standardized sampling) if done in a spatially explicit context, and following standardized protocols, could ultimately inform predictive modeling frameworks for soil ecosystems to track the fulfillment of global/national biodiversity targets, policy support, and decision-making. Taken together, our study shows important spatial and environmental gaps across different taxa and functions that future macroecological research should target, and a need to collect temporal datasets to explore if current aboveground biodiversity declines are found in belowground taxa. With the identification of global spatial, taxonomic, and functional blind spots, and the definition of priority actions for global soil macroecological research ${ }^{74}$, our synthesis highlights the need for action to facilitate a global soil monitoring system that overcomes the current limitations.

\section{Methods}

Literature selection and data processing. We created a dataset by collecting published literature on macroecological studies of soil biodiversity and ecosystem 


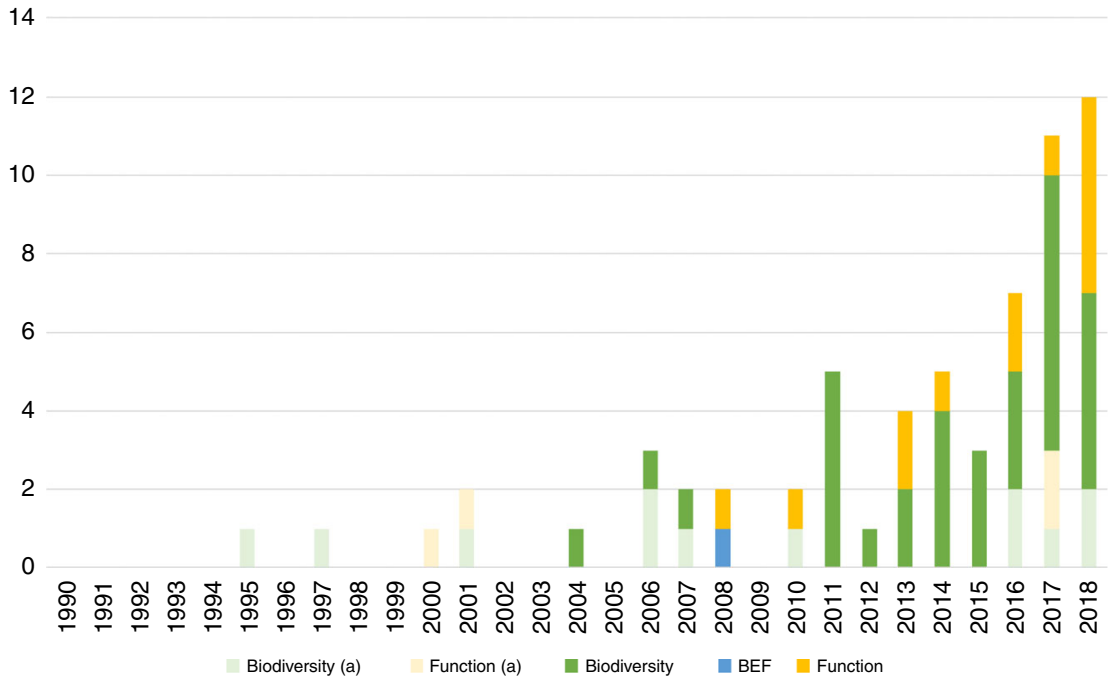

Fig. 4 Accumulated number of papers screened for this analysis. Studies were classified in soil biodiversity, function or biodiversity, and ecosystem function (BEF), according to the subject of the study (see Table 2). a corresponds to the number of studies that were not included due to the underlying data not being suited for this analysis (e.g., based on national level information) or data availability issues. Overall, $72.6 \%$ of the total number of studies identified as suitable were included in the analysis ranging from 2004 to 2018.

functions. For this literature search, we conducted a search in the Web of Knowledge database in November 2018 within papers published between 1945 and 2018 using the keywords: (Global* OR Continental OR latitud*) AND (soil* OR belowground) AND (*function* OR *diversity OR organism* OR biota OR animal* OR invert* OR fauna*) AND distribution AND (*mycorrhiz* OR microb* OR nematod* OR bacteria* OR ant* OR fung* OR invertebrate* OR earthworm* OR protist* OR eukaryot* OR collembola* OR rotifer* OR archaea OR formic* OR mite* OR termite* OR arthropod* OR respiration OR decomposition OR nitrogen-cycling OR nutrient cycling OR water infiltration OR aggregate* OR bioturbation OR biomass). These keywords were selected to encompass the maximum number of published studies, which often use a variety of expressions for describing soil biodiversity and function. Additionally, we included studies found in the references of the papers returned by the database, as well as opportunistically gathering additional studies, such as from personal bibliographic databases of global soil studies.

The initial Web of Science search returned 1203 studies, which were screened for the following three inclusion criteria: (1) studies dealing with soil taxa and/or soil ecosystem functions; (2) studies spanning more than one continent with more than single locations in each continent (the Pacific islands not included in any particular continent were counted as an individual continent, contributing to the inclusion of some studies); and (3) studies that span across an entire continent (i.e., a study focussing only on Europe would not be included but if larger scales would be assessed - e.g., across Eurasia - the study would be included). From these, the number of studies was reduced to 58 that, after being complemented with additional studies, resulted in a dataset with 62 studies dealing with processes and patterns of soil biodiversity and/or soil ecosystem function across global gradients ranging from $1995^{117}$ to $2018^{118}$ (Fig. 4, Table 2).

The 62 studies selected were then classified according to the taxon and/or function that was subject of the paper and screened for the availability of point coordinates for the sampling sites underlying the study (Table 2). We obtained the locations of the sampling sites that supported each manuscript, either by using published data or by contacting the corresponding authors of the publications. Papers including only national or regional level information were not included in this analysis. This was not done because of any consideration about the quality of the study nor related to bad reporting, but rather because of the lack of comparable data across studies. Overall, $\sim 72.6 \%$ (45 studies) of the total number of studies identified were included in the analysis (see Table 2 for more details). This allowed us to cover ten different taxa and five (from a total of seven) ecosystem functions with important relevance for biogeochemical cycles $2,119,120$ and the supply of key ecosystem services ${ }^{1,3}$ (Fig. 1; Table 2).

Available pairs of coordinates were then georeferenced and projected to WGS84 to create a dataset comprising all individual studies. The geographic coordinates of the sites were included based on the data provided by the studies and no spatial corrections were made (Fig. 1). In the manuscript, sampling sites refer to unique $\mathrm{X}$, $\mathrm{Y}$ pairs of coordinates that represent individual locations. As a final step, sampling sites located outside of the terrestrial scope of this paper - which excludes Antarctica and Greenland - were removed from the subsequent analysis.

Completeness and estimation of global representation. One of the main objectives of this paper is to describe the ability of current soil macroecological
Table 2 List of studies included in the current assessment.

\begin{tabular}{lll} 
Soil biodiversity & Included studies & Not included studies \\
\hline Bacteria & $10,14,35,66,70,120,139-$ & $119,146-149$ \\
& 145 & \\
Archaea & $70,120,141,142,150$ & 146,149 \\
Fungi & $45,110,141,142,145,151-156$ & $119,146,157-159$ \\
Protista & $70,160,161$ & $117,162-164$ \\
Nematoda & $13,44,165,166$ & 119 \\
Rotifera & 166,167 & - \\
Collembola & 168 & 119 \\
Acari & 166,168 & 119,169 \\
Formicoidea & $34,46,170$ & - \\
Oligochaeta & $43,46,118,166,168,171$ & - \\
Soil functions & - & - \\
Decomposition & $67,72,168$ & 172 \\
Soil respiration & $63,71,116,173-175$ & 176 \\
Nutrient cycling & 177 & - \\
Water infiltration & 178,179 & - \\
Bioturbation & - & 180 \\
Soil aggregate & - & 181 \\
stability & & \\
\hline
\end{tabular}

aGiven the thematic scope of some studies, an individual study can be included in more than one taxon/function.

research to capture the diversity of conditions affecting the soil realm, here described as the bulk of characteristics encompassing the soil (including physical and chemical properties), climate (including properties that affect soil conditions e.g., related to soil humidity and temperature), geomorphology (including global topographic properties), and aboveground diversity ${ }^{1,41}$. With this definition, we identified 15 environmental and diversity descriptor variables of the soil realm (Table 3) that we used to characterize how the overall sampling locations for each study capture the global environmental and aboveground diversity scope. Initial calculations were made using ArcGIS and ArcPy at the original resolution of the different datasets although, for the final spatial mapping and integration, all datasets were harmonized to an $\sim 1 \mathrm{~km}^{2}$ (at the equator) resolution using a resampling algorithm without changing the original values - i.e., focussing only on pixel disaggregation with a nearest neighbor classifier.

For each study, we examined how these sample-based distributions capture the diversity of global conditions with the purpose of finding the "blind spots" of global soil ecosystem research corresponding to underrepresented areas of low environmental and aboveground diversity representation. To do this, we compared the global histogram of each of these environmental and aboveground diversity variables (Table 3) with the one obtained using the sampling sites for every 
Table 3 Environmental variables defining the soil realm.

Environmental variable

Soil carbon

Soil pH

Clay content

Sand content

Silt content

Soil type

Mean annual temperature

Mean annual precipitation

Temperature seasonality

Precipitation seasonality

Aridity

Potential evapotranspiration

Elevation

Land cover type

Plant diversity

\section{Dataset}

Reference

SoilGRIDS - global soil information based on automated mapping

SoilGRIDS - global soil information based on automated mapping

SoilGRIDS - global soil information based on automated mapping

SoilGRIDS - global soil information based on automated mapping

SoilGRIDS - global soil information based on automated mapping

SoilGRIDS - global soil information based on automated mapping

CHELSA - Climatologies at high resolution for the earth's land surface areas

CHELSA - Climatologies at high resolution for the earth's land surface areas

CHELSA - Climatologies at high resolution for the earth's land surface areas

CHELSA - Climatologies at high resolution for the earth's land surface areas

CGIAR-CSI - Global aridity database

CGIAR-CSI - Global potential evapotranspiration database

GMTED2010 - Global Multi-resolution Terrain Elevation Data

ESA CCI - Global Land Cover database

Global plant diversity
127

127

127

127

127

127

129

129

129

129

182,183

182,183

130

131

73 particular study. These histograms were classified using a natural breaks (Jenks) method $^{121}$, with the exception of land cover and soil type for which the original categorical classification was maintained. This procedure allowed us to identify particular ranges of environmental and diversity conditions that are overrepresented in current literature and not assume total coverage by just looking at the spatial distribution of sampling sites. For example, having one sampling site in the tropics may wrongly give the impression that tropical regions are covered when in fact this sampling site can only cover a very small range of the total tropical spectrum. Given the small scale differences in soil communities, by contrast with other aboveground taxa, this overrepresentation of specific conditions in detriment of others is of the utmost importance as it can produce important interpretation biases and knowledge limitations.

Second, for each study, we overlaid the spatial representation of all variables to include the mean and median distribution and the standard deviation across environmental variables. In order to have taxonomic and functional representations (e.g., for Bacteria, fungi, decomposition, etc.), we replicated the procedure by including all the studies identified for each taxon and function. In parallel, we used global biomes ${ }^{122}$ as a spatial stratifier to understand global biases in soil biodiversity and function data and representation. Finally, to assess the representation of soil diversity and climate conditions, it is not enough to evaluate them independently of each other. Therefore, we combined the previously classified variables (the spatial distributions of each classified variable can be found in Supplementary Figs. 5-9) in three different groups (Supplementary Fig. 10): (a) land cover (including the combination of land cover, plant diversity and elevation); (b) soils (including the combination of organic carbon, sand content, and $\mathrm{pH}$ ); and (c) climate (including the combination of mean precipitation and temperature, and their seasonality). We finally overlayed these mapped combinations with the distribution data from each study in order to understand which combinations have the highest number of redundant studies, i.e., more than one study covering the same environmental combination.

Finally, we applied a statistical method based on the calculation of a multidimensional distance (considering all continuous environmental variables) based on mahalanobis distance ${ }^{123,124}$. For each study, we calculated and mapped the Mahalanobis distance of all locations to the center of the observed distribution given by the sample distribution of each study. This distance is useful to detect outliers in point cloud distributions that are assumed to follow a multivariate Normal distribution 123,124 . When each of the variables is normally distributed, the Mahalanobis distance follows a $\chi^{2}$ distribution with d degrees of freedom, where $\mathrm{d}$ corresponds to the dimension of the multidimensional space (i.e. the number of environmental variables used) ${ }^{123,124}$. Figure 3 uses a color gradient to indicate the quantile of the Chi squared distribution with 13 degrees of freedom that each $x y$ coordinate belongs to Mallavan et al. ${ }^{125}$.

We acknowledge that sampling schemes should in the future consider the amount of diversity represented in each region and, therefore, match the sampling effort with estimates of completeness coverage of actual composition values ${ }^{126}$. Nevertheless, due to the lack of access to the actual diversity and functional data (apart from publicly available datasets) and, more importantly, to the assumption that current global soil biodiversity hotspots are either poorly characterized (due to data constraints) or fail to account for the diversity of environmental conditions present in the globe, we implemented the current approach as an alternative to highlight the environmental coverage of current macroecological studies. In the future, with more studies shedding more light on the global distribution of soil biodiversity, studies and monitoring initiatives should probably focus on approaches that use the "novelty" of each new sample to infer how (in)complete the description of biodiversity is ${ }^{126}$.

As the current analysis was conducted as a global analysis without a regional segmentation (e.g., without partitioning the analysis per continent), sampling sites in one continent (e.g., sampling sites covering high altitude areas in Europe) may influence the coverage in other continents (e.g., may identify areas in North and South America as being partially covered). Although this may lead to the overrepresentation of some areas (and consequent underrepresentation of others), our main intent is to understand how current macroecological literature is capturing the diversity of global soil conditions.

Reporting summary. Further information on research design is available in the Nature Research Reporting Summary linked to this article.

\section{Data availability}

All data is available as a single dataset including all soil biodiversity and function locations with reference to the respective manuscripts from which they were extracted. It can be found here $10.6084 / \mathrm{m}$ 9.figshare. 12581306 and here $10.6084 / \mathrm{m} 9$.

figshare.12581306.

Received: 5 March 2019; Accepted: 10 July 2020; Published online: 03 August 2020

\section{References}

1. Wall, D. H. et al. Soil Ecology And Ecosystem Services. p. 406 (Oxford University Press, 2012).

2. Blouin, M. et al. A review of earthworm impact on soil function and ecosystem services. Eur. J. Soil Sci. 64, 161-182 (2013).

3. Baveye, P. C., Baveye, J. \& Gowdy, J. Soil 'Ecosystem' services and natural capital: critical appraisal of research on uncertain ground. Front. Environ. Sci. Eng. China 4, 1-49 (2016).

4. Bardgett, R. D. \& van der Putten, W. H. Belowground biodiversity and ecosystem functioning. Nature 515, 505-511 (2014).

5. Heemsbergen \& Hal, V. Biodiversity effects on soil processes explained by interspecific functional dissimilarity biodiversity effects on soil processes explained by interspecific. Science 306, 8-10 (2004).

6. Reich, P. B. et al. Impacts of biodiversity loss escalate through time as redundancy fades. Science 336, 589-592 (2012).

7. Schuldt, A. et al. Biodiversity across trophic levels drives multifunctionality in highly diverse forests. Nat. Commun. 9, 2989 (2018).

8. Risch, A. C. et al. Size-dependent loss of aboveground animals differentially affects grassland ecosystem coupling and functions. Nat. Commun. 9, 3684 (2018).

9. Soliveres, S. et al. Biodiversity at multiple trophic levels is needed for ecosystem multifunctionality. Nature 536, 456-459 (2016).

10. Maestre, F. T. et al. Increasing aridity reduces soil microbial diversity and abundance in global drylands. Proc. Natl Acad. Sci. USA 112, 201516684 (2015).

11. Manning, P. et al. Redefining ecosystem multifunctionality. Nat. Ecol. Evol. 2, 427-436 (2018).

12. Maestre, F. T. et al. Plant species richness and ecosystem multifunctionality in global drylands. Science 335, 214-218 (2012).

13. Song, D. et al. Large-scale patterns of distribution and diversity of terrestrial nematodes. Appl. Soil Ecol. 114, 161-169 (2017). 
14. Delgado-Baquerizo, M. et al. Palaeoclimate explains a unique proportion of the global variation in soil bacterial communities. Nat. Ecol. Evol. 1, 1339-1347 (2017).

15. Pärtel, M., Bennett, J. A. \& Zobel, M. Macroecology of biodiversity: disentangling local and regional effects. New Phytol. 211, 404-410 (2016)

16. Meyer, C., Kreft, H., Guralnick, R. \& Jetz, W. Global priorities for an effective information basis of biodiversity distributions. Nat. Commun. 6, 8221 (2015).

17. Dornelas, M. et al. Assemblage time series reveal biodiversity change but not systematic loss. Science 344, 296-299 (2014).

18. Hansen, M. C. et al. High-resolution global maps of 21st-century forest cover change. Science 342, 850-853 (2013).

19. Grace, J. B. et al. Integrative modelling reveals mechanisms linking productivity and plant species richness. Nature 529, 390-393 (2016).

20. Liang, J. et al. Positive biodiversity-productivity relationship predominant in global forests. Science 354, aaf8957 (2016).

21. Duffy, J. E., Godwin, C. M. \& Cardinale, B. J. Biodiversity effects in the wild are common and as strong as key drivers of productivity. Nature 549, 261-264 (2017).

22. van der Plas, F. et al. Jack-of-all-trades effects drive biodiversity-ecosystem multifunctionality relationships in European forests. Nat. Commun. 7, 11109 (2016).

23. van der Plas, F. et al. Continental mapping of forest ecosystem functions reveals a high but unrealised potential for forest multifunctionality. Ecol. Lett. 21, 31-42 (2018)

24. Delgado-Baquerizo, M. et al. Microbial diversity drives multifunctionality in terrestrial ecosystems. Nat. Commun. 7, 10541 (2016).

25. Cameron, E. K. et al. Global gaps in soil biodiversity data. Nat. Ecol. Evol. 2, 1042-1043 (2018).

26. Wetzel, F. T. et al. Unlocking biodiversity data: prioritization and filling the gaps in biodiversity observation data in Europe. Biol. Conserv. 221, 78-85 (2018).

27. Amano, T. \& Sutherland, W. J. Four barriers to the global understanding of biodiversity conservation: wealth, language, geographical location and security. Proc. Biol. Sci. 280, 20122649 (2013).

28. Eisenhauer, N., Bonn, A. \& Guerra, C. A. Recognizing the quiet extinction of invertebrates. Nat. Commun. 10, 50 (2019).

29. Pereira, H. M., Navarro, L. M. \& Martins, I. S. Global biodiversity change: the bad, the good, and the unknown. Annu. Rev. Environ. Resour. 37, 25-50 (2012).

30. Paleari, S. Is the European Union protecting soil? A critical analysis of Community environmental policy and law. Land Use Policy 64, 163-173 (2017).

31. Meyer, C., Weigelt, P. \& Kreft, H. Multidimensional biases, gaps and uncertainties in global plant occurrence information. Ecol. Lett. 19, 992-1006 (2016).

32. Costello, M. J., Michener, W. K., Gahegan, M., Zhang, Z.-Q. \& Bourne, P. E. Biodiversity data should be published, cited, and peer reviewed. Trends Ecol. Evol. 28, 454-461 (2013).

33. Bingham, H. C., Doudin, M. \& Weatherdon, L. V. The biodiversity informatics landscape: elements, connections and opportunities. 3, e14059 (2017)

34. Gibb, H. et al. A global database of ant species abundances. Ecology 98, 883-884 (2017).

35. Thompson, L. R. et al. A communal catalogue reveals Earth's multiscale microbial diversity. Nature 551, 457-463 (2017).

36. Overmann, J., Abt, B. \& Sikorski, J. Present and future of culturing bacteria. Annu. Rev. Microbiol. 71, 711-730 (2017).

37. de Groot, R. S., Alkemade, R., Braat, L., Hein, L. \& Willemen, L. Challenges in integrating the concept of ecosystem services and values in landscape planning, management and decision making. Ecol. Complex. 7, 260-272 (2010).

38. Stewart, G. Meta-analysis in applied ecology. Biol. Lett. 6, 78-81 (2010).

39. Rillig, M. C. et al. Biodiversity research: data without theory-theory without data. Front. Ecol. Evol. 3, 20 (2015).

40. Coleman, D. C., Callaham, M. A. \& Crossley, D. A., Jr. Fundamentals of Soil Ecology. (Academic Press, 2017).

41. Lavelle, P. \& Spain, A. Soil Ecology. (Springer Science \& Business Media, 2001).

42. Hudson, L. N. et al. The database of the PREDICTS (Projecting Responses of Ecological Diversity In Changing Terrestrial Systems) project. Ecol. Evol. 7, 145-188 (2017).

43. Phillips, H. R. P. et al. 2019. Global distribution of earthworm diversity. Science https://doi.org/10.1126/science.aax4851 (2019).

44. van den Hoogen J., et al. Soil nematode abundance and functional group composition at a global scale. Nature https://doi.org/10.1038/s41586-0191418-6 (2019).

45. Tedersoo, L. et al. Global diversity and geography of soil fungi. Science 346, 1256688 (2014).

46. Orgiazzi, A. et al. Global Soil Biodiversity Atlas (JRC and the Global Soil Biodiversity Initiative, 2016).
47. Guenard, B., Weiser, M. D. \& Gomez, K. The Global Ant Biodiversity Informatics (GABI) database: synthesizing data on the geographic distribution of ant species (Hymenoptera: Formicidae). Myrmecol. News 24, 83-89 (2017).

48. Nielsen, U. N. et al. The enigma of soil animal species diversity revisited: the role of small-scale heterogeneity. PLoS ONE 5, e11567 (2010).

49. Lavelle, P. et al. Soil invertebrates and ecosystem services. Eur. J. Soil Biol. 42 S3-S15 (2006).

50. Evans, T. A., Dawes, T. Z., Ward, P. R. \& Lo, N. Ants and termites increase crop yield in a dry climate. Nat. Commun. 2, 262-267 (2011).

51. Eisenhauer, N., Bowker, M. A., Grace, J. B. \& Powell, J. R. From patterns to causal understanding: Structural equation modeling (SEM) in soil ecology. Pedobiologia 58, 65-72 (2015).

52. Isbell, F. et al. Biodiversity increases the resistance of ecosystem productivity to climate extremes. Nature 526, 574-577 (2015).

53. Craven, D. et al. Multiple facets of biodiversity drive the diversity-stability relationship. Nat. Ecol. Evol. 2, 1579-1587 (2018).

54. Fraser, L. H. et al. Plant ecology. Worldwide evidence of a unimodal relationship between productivity and plant species richness. Science 349, 302-305 (2015).

55. Newbold, T. et al. Global effects of land use on local terrestrial biodiversity. Nature 520, 45-50 (2015).

56. Borgman, C. L., Wallis, J. C. \& Enyedy, N. Little science confronts the data deluge: habitat ecology, embedded sensor networks, and digital libraries. Int. J. Digit. Lib. 7, 17-30 (2007).

57. Hampton, S. E. et al. Big data and the future of ecology. Front. Ecol. Environ. 11, 156-162 (2013)

58. Pey, B. et al. Current use of and future needs for soil invertebrate functional traits in community ecology. Basic Appl. Ecol. 15, 194-206 (2014).

59. Tsiafouli, M. A. et al. Intensive agriculture reduces soil biodiversity across Europe. Glob. Chang. Biol. 21, 973-985 (2015).

60. Blankinship, J. C., Niklaus, P. A. \& Hungate, B. A. A meta-analysis of responses of soil biota to global change. Oecologia 165, 553-565 (2011).

61. Wheeler, Q. D., Raven, P. H. \& Wilson, E. O. Taxonomy: impediment or expedient? Science 303, 285 (2004).

62. Delgado-Baquerizo, M. \& Eldridge, D. J. Cross-biome drivers of soil bacterial alpha diversity on a worldwide scale. Ecosystems 22, 1-12 (2019).

63. Hursh, A. et al. The sensitivity of soil respiration to soil temperature, moisture, and carbon supply at the global scale. Glob. Chang. Biol. 23, 2090-2103 (2017).

64. Wang, Q., Liu, S. \& Tian, P. Carbon quality and soil microbial property contro the latitudinal pattern in temperature sensitivity of soil microbial respiration across Chinese forest ecosystems. Glob. Chang. Biol. 24, 2841-2849 (2018).

65. Prăvălie, R. Drylands extent and environmental issues. A global approach. Earth-Sci. Rev. 161, 259-278 (2016).

66. Delgado-baquerizo, M. et al. A global atlas of the dominant bacteria found in soil. Science 325, 320-325 (2018).

67. Djukic, I. et al. Early stage litter decomposition across biomes. Sci. Total Environ. (2018).

68. Cowan, D. A. et al. Microbiomics of Namib Desert habitats. Extremophiles 24, 17-29 (2020)

69. Rutgers, M. et al. Mapping earthworm communities in Europe. Appl. Soil Ecol. 97, 98-111 (2016)

70. Delgado-Baquerizo, M. et al. Ecological drivers of soil microbial diversity and soil biological networks in the Southern Hemisphere. Ecology 99, 583-596 (2018).

71. Chen, S., Zou, J., Hu, Z., Chen, H. \& Lu, Y. Global annual soil respiration in relation to climate, soil properties and vegetation characteristics: summary of available data. Agric. For. Meteorol. 198-199, 335-346 (2014).

72. Zhang, D., Hui, D., Luo, Y. \& Zhou, G. Rates of litter decomposition in terrestrial ecosystems: global patterns and controlling factors. J. Plant Ecol. 1, 85-93 (2008).

73. Kreft, H. \& Jetz, W. Global patterns and determinants of vascular plant diversity. Proc. Natl Acad. Sci. USA 104, 5925-5930 (2007).

74. Cameron, E. et al. Global mismatches in aboveground and belowground biodiversity. Conserv. Biol. 33, 1187-1192 (2019)

75. Scherber, C. et al. Bottom-up effects of plant diversity on multitrophic interactions in a biodiversity experiment. Nature 468, 553-556 (2010).

76. Eisenhauer, N. et al. Plant diversity effects on soil food webs are stronger than those of elevated $\mathrm{CO} 2$ and $\mathrm{N}$ deposition in a long-term grassland experiment. Proc. Natl Acad. Sci. USA 110, 6889-6894 (2013).

77. Lange, $M$. et al. Plant diversity increases soil microbial activity and soil carbon storage. Nat. Commun. 6, 6707 (2015).

78. Menegotto, A. \& Rangel, T. F. Mapping knowledge gaps in marine diversity reveals a latitudinal gradient of missing species richness. Nat. Commun. 9, 4713 (2018)

79. Eisenhauer, N. et al. Priorities for research in soil ecology. Pedobiologia 63, 1-7 (2017).

80. Hallmann, C. A. et al. More than 75 percent decline over 27 years in total flying insect biomass in protected areas. PLoS ONE 12, e0185809 (2017). 
81. Dirzo, R. et al. Defaunation in the Anthropocene. Science 345, 401-406 (2014).

82. Cardinale, B. J. et al. Biodiversity loss and its impact on humanity. Nature 489, 326-326 (2012).

83. Titeux, N. et al. Biodiversity scenarios neglect future land-use changes. Glob. Chang. Biol. 22, 2505-2515 (2016).

84. Popp, A. et al. Land-use futures in the shared socio-economic pathways. Glob. Environ. Change 42, 331-345 (2017).

85. Dai, A. Increasing drought under global warming in observations and models. Nat. Clim. Chang. 3, 52 (2012).

86. Kharin, V. V., Zwiers, F. W., Zhang, X. \& Hegerl, G. C. Changes in temperature and precipitation extremes in the IPCC ensemble of global coupled model simulations. J. Clim. 20, 1419-1444 (2007).

87. Parmesan, C. \& Yohe, G. A globally coherent fingerprint of climate change impacts across natural systems. Nature 421, 37-42 (2003).

88. Bronselaer, B. et al. Change in future climate due to Antarctic meltwater. Nature 564, 53-58 (2018).

89. Collins, M., Knutti, R., Arblaster, J., Dufresne, J. L. \& Fichefet, T. Long-term climate change: projections, commitments and irreversibility. Chapter 12 (eds T. Stocker et al) 1029-1136 (Cambridge University Press, 2013).

90. Delgado-Baquerizo, M., Eldridge, D. J., Hamonts, K. \& Singh, B. K. Ant colonies promote the diversity of soil microbial communities. ISME J. https:// doi.org/10.1038/s41396-018-0335-2 (2019).

91. Wardle, D. A. et al. Ecological linkages between aboveground and belowground biota. Science 304, 1629-1633 (2004).

92. Thomson, S. A. et al. Taxonomy based on science is necessary for global conservation. PLoS Biol. 16, e2005075 (2018).

93. Drew, L. W. Are we losing the science of taxonomy? Bioscience 61, 942-946 (2011).

94. Paknia, O., Sh., H. R. \& Koch, A. Lack of well-maintained natural history collections and taxonomists in megadiverse developing countries hampers global biodiversity exploration. Organ. Divers. Evol. 15, 619-629 (2015).

95. Prathapan, K. D. et al. When the cure kills-CBD limits biodiversity research. Science 360, 1405-1406 (2018).

96. Neumann, D. et al. Global biodiversity research tied up by juridical interpretations of access and benefit sharing. Org. Divers. Evol. 18, 1-12 (2017).

97. Leimu, R. \& Koricheva, J. What determines the citation frequency of ecological papers? Trends Ecol. Evol. 20, 28-32 (2005).

98. Hugerth, L. W. \& Andersson, A. F. Analysing microbial community composition through amplicon sequencing: from sampling to hypothesis testing. Front. Microbiol. 8, 1561 (2017).

99. Terrat, S. et al. Meta-barcoded evaluation of the ISO standard 11063 DNA extraction procedure to characterize soil bacterial and fungal community diversity and composition. Microb. Biotechnol. 8, 131-142 (2015).

100. Kõljalg, U., Larsson, K. H. \& Abarenkov, K. UNITE: a database providing web-based methods for the molecular identification of ectomycorrhizal fungi. New Phytol 166, 1063-1068 (2005).

101. Mathieu, J., Caro, G. \& Dupont, L. Methods for studying earthworm dispersal. Appl. Soil Ecol. 123, 339-344 (2018).

102. Pauchard, N. Access and benefit sharing under the convention on biological diversity and its protocol: what can some numbers tell us about the effectiveness of the regulatory regime? Resources 6, 11 (2017).

103. Saha, S., Saha, S. \& Saha, S. K. Barriers in Bangladesh. Elife 7, e41926 (2018).

104. Prathapan, K. D. \& Rajan, P. D. Biodiversity access and benefit-sharing: weaving a rope of sand. Curr. Sci. 100, 290-293 (2011).

105. van der Linde, S. et al. Environment and host as large-scale controls of ectomycorrhizal fungi. Nature 558, 243-248 (2018).

106. Terrat, S. et al. Mapping and predictive variations of soil bacterial richness across France. PLoS ONE 12, e0186766 (2017).

107. Makiola, A., et al. Key questions for next-generation biomonitoring. Front. Environ. Sci. 7, 197 (2020).

108. Maestre, F. T. \& Eisenhauer, N. Recommendations for establishing global collaborative networks in soil ecology. Soil Organ. 91, 73-85 (2019).

109. Phillips, H. R. P. et al. Red list of a black box. Nat. Ecol. Evol. 1, 0103 (2017).

110. Davison, J. et al. Microbial island biogeography: isolation shapes the life history characteristics but not diversity of root-symbiotic fungal communities. ISME J. https://doi.org/10.1038/s41396-018-0196-8 (2018).

111. Overmann, J. Significance and future role of microbial resource centers. Syst. Appl. Microbiol. 38, 258-265 (2015).

112. Overmann, J. \& Scholz, A. H. Microbiological research under the nagoya protocol: facts and fiction. Trends Microbiol. 25, 85-88 (2017).

113. Bockmann, F. A. et al. Brazil's government attacks biodiversity. Science 360, 865 (2018).

114. Scbd-Unep. Nagoya Declaration on Biodiversity in Development Cooperation. 2 (UNEP, 2010).

115. Perrings, C. et al. Ecosystem services for 2020. Science 330, 323-324 (2010).

116. Bond-Lamberty, B. \& Thomson, A. A global database of soil respiration data. Biogeosci. Discuss. 7, 1321-1344 (2010).
117. Bamforth, S. S. Interpreting soil ciliate biodiversity. Plant Soil 170, 159-164 (1995).

118. Mathieu, J. EGrowth: a global database on intraspecific body growth variability in earthworm. Soil Biol. Biochem. 122, 71-80 (2018).

119. Fierer, N., Strickland, M. S., Liptzin, D., Bradford, M. A. \& Cleveland, C. C. Global patterns in belowground communities. Ecol. Lett. 12, 1238-1249 (2009).

120. Nelson, M. B., Martiny, A. C. \& Martiny, J. B. H. Global biogeography of microbial nitrogen-cycling traits in soil. Proc. Natl Acad. Sci. USA 113, 8033-8040 (2016)

121. Chen, J., Yang, S. T., Li, H. W., Zhang, B. \& Lv, J. R. Research on geographical environment unit division based on the method of natural breaks (Jenks). ISPRS - International Archives of the Photogrammetry, Remote Sensing and Spatial Information Sciences. Vol. XL-4/W3, pp. 47-50 (2013).

122. Dinerstein, E. et al. An ecoregion-based approach to protecting half the terrestrial realm. Bioscience 67, 534-545 (2017).

123. Rousseeuw, P. J. \& van Zomeren, B. C. Unmasking multivariate outliers and leverage points. J. Am. Stat. Assoc. 85, 633-639 (1990).

124. Jackson, D. A. \& Chen, Y. Robust principal component analysis and outlier detection with ecological data. Environmetrics 15, 129-139 (2004).

125. Mallavan B. P., Minasny B., McBratney A. B., in Digital Soil Mapping. pp. 137-150 (Springer, Dordrecht, 2010).

126. Chao, A. \& Jost, L. Coverage-based rarefaction and extrapolation: standardizing samples by completeness rather than size. Ecology $\mathbf{9 3}$ 2533-2547 (2012).

127. Hengl, T. et al. SoilGrids $1 \mathrm{~km}$-global soil information based on automated mapping. PLoS ONE 9, e105992 (2014).

128. Trabucco, A., Zomer, R. J., Bossio, D. A., van Straaten, O. \& Verchot, L. V. Climate change mitigation through afforestation/reforestation: a global analysis of hydrologic impacts with four case studies. Agric. Ecosyst. Environ. 126, 81-97 (2008)

129. Karger, D. N. et al. Climatologies at high resolution for the Earth land surface areas. Sci. Data 4, 1-19 (2017).

130. Global Multi-resolution Terrain Elevation Data 2010 (GMTED2010) | The Long Term Archive. Available at: https://ta.cr.usgs.gov/GMTED2010. Accessed on 6 December 2018.

131. European Space Agency. ESA - Land Cover CCI - Product User Guide Version 2.0. (2017).

132. Frostegård, Å., Tunlid, A. \& Bååth, E. Microbial biomass measured as total lipid phosphate in soils of different organic content. J. Microbiol. Methods 14, 151-163 (1991)

133. Campbell, C. D., Chapman, S. J., Cameron, C. M., Davidson, M. S. \& Potts, J. M. A rapid microtiter plate method to measure carbon dioxide evolved from carbon substrate amendments so as to determine the physiological profiles of soil microbial communities by using whole soil. Appl. Environ. Microbiol. 69, 3593-3599 (2003).

134. Eppo, P. M. Nematode extraction. EPPO Bull. 43, 471-495 (2013)

135. ISO/FDIS. Soil Quality - Sampling Of Soil Invertebrates - Part 1: Hand-sorting And Extraction Of Earthworms. (ISO, 2018).

136. ISO. Soil quality - Sampling Of Soil Invertebrates - Part 4: Sampling, Extraction And Identification Of Soil-Inhabiting Nematodes. (ISO, 09-2011).

137. Hunter, P. A. DEAL for open access: The negotiations between the German DEAL project and publishers have global implications for academic publishing beyond just Germany. EMBO Rep. 19, e46317 (2018).

138. Knapp, A. K. et al. Past, present, and future roles of long-term experiments in the LTER network. Bioscience 62, 377-389 (2012).

139. Bahram, M. et al. Structure and function of the global topsoil microbiome. Nature 560, 233-237 (2018)

140. Ramirez, K. S. et al. Detecting macroecological patterns in bacterial communities across independent studies of global soils. Nat. Microbiol. 3, 1-8 (2017).

141. Leff, J. W. et al. Consistent responses of soil microbial communities to elevated nutrient inputs in grasslands across the globe. Proc. Natl Acad. Sci. USA 112, 10967-10972 (2015).

142. Gilbert, J. A., Jansson, J. K. \& Knight, R. The earth microbiome project: successes and aspirations. BMC Biol. 12, 69 (2014).

143. Fierer, N. \& Jackson, R. B. The diversity and biogeography of soil bacterial communities. Proc. Natl Acad. Sci. USA 103, 626-631 (2006).

144. Darcy, J. L., Lynch, R. C., King, A. J., Robeson, M. S. \& Schmidt, S. K. Global distribution of Polaromonas phylotypes-evidence for a highly successful dispersal capacity. PLoS ONE 6, e23742 (2011).

145. Hendershot, J. N., Read, Q. D., Henning, J. A., Sanders, N. J. \& Classen, A. T. Consistently inconsistent drivers of microbial diversity and abundance at macroecological scales. Ecology 98, 1757-1763 (2017).

146. Locey, K. J. \& Lennon, J. T. Scaling laws predict global microbial diversity. Proc. Natl Acad. Sci. USA 113, 5970-5975 (2016).

147. Lozupone, C. A. \& Knight, R. Global patterns in bacterial diversity. Proc. Natl Acad. Sci. USA 104, 11436-11440 (2007). 
148. Neal, A. L. et al. Phylogenetic distribution, biogeography and the effects of land management upon bacterial non-specific Acid phosphatase Gene diversity and abundance. Plant Soil 427, 175-189 (2018).

149. Shoemaker, W. R., Locey, K. J. \& Lennon, J. T. A macroecological theory of microbial biodiversity. Nat. Ecol. Evol. 1, 107 (2017).

150. Bates, S. T. et al. Examining the global distribution of dominant archaeal populations in soil. ISME J. 5, 908-917 (2011).

151. Davison, J. et al. Global assessment of arbuscular mycorrhizal fungus diversity reveals very low endemism. Science 349, 970-973 (2015).

152. Kivlin, S. N., Hawkes, C. V. \& Treseder, K. K. Global diversity and distribution of arbuscular mycorrhizal fungi. Soil Biol. Biochem. 43, 2294-2303 (2011).

153. Pärtel, M. et al. Historical biome distribution and recent human disturbance shape the diversity of arbuscular mycorrhizal fungi. New Phytol. 216, 227-238 (2017).

154. Põlme, S. et al. Biogeography of ectomycorrhizal fungi associated with alders (Alnus spp.) in relation to biotic and abiotic variables at the global scale. New Phytol. 198, 1239-1249 (2013).

155. Sharrock, R. A. et al. A global assessment using PCR techniques of mycorrhizal fungal populations colonising Tithonia diversifolia. Mycorrhiza 14, 103-109 (2004).

156. Tedersoo, L. et al. Towards global patterns in the diversity and community structure of ectomycorrhizal fungi. Mol. Ecol. 21, 4160-4170 (2012).

157. Öpik, M., Moora, M., Liira, J. \& Zobel, M. Composition of root-colonizing arbuscular mycorrhizal fungal communities in different ecosystems around the globe: arbuscular mycorrhizal fungal communities around the globe. J. Ecol. 94, 778-790 (2006).

158. Öpik, M. et al. The online database MaarjAM reveals global and ecosystemic distribution patterns in arbuscular mycorrhizal fungi (Glomeromycota). New Phytol. 188, 223-241 (2010).

159. Stürmer, S. L., Bever, J. D. \& Morton, J. B. Biogeography of arbuscular mycorrhizal fungi (Glomeromycota): a phylogenetic perspective on species distribution patterns. Mycorrhiza 28, 587-603 (2018).

160 . Bates, S. T. et al. Global biogeography of highly diverse protistan communities in soil. ISME J. 7, 652-659 (2013).

161. Lara, E., Roussel-Delif, L. \& Fournier, B. Soil microorganisms behave like macroscopic organisms: patterns in the global distribution of soil euglyphid testate amoebae. J. Biogeogr. 43, 520-532 (2016).

162. Finlay, B. J., Esteban, G. F., Clarke, K. J. \& Olmo, J. L. Biodiversity of terrestrial protozoa appears homogeneous across local and global spatial scales. Protist 152, 355-366 (2001).

163. Chao, A., C. Li, P., Agatha, S. \& Foissner, W. A statistical approach to estimate soil ciliate diversity and distribution based on data from five continents. Oikos 114, 479-493 (2006).

164. Foissner, W. Global soil ciliate (Protozoa, Ciliophora) diversity: a probabilitybased approach using large sample collections from Africa, Australia and Antarctica. Biodivers. Conserv. 6, 1627-1638 (1997).

165. Nielsen, U. N. et al. Global-scale patterns of assemblage structure of soil nematodes in relation to climate and ecosystem properties: Global-scale patterns of soil nematode assemblage structure. Glob. Ecol. Biogeogr. 23, 968-978 (2014).

166. Wu, T., Ayres, E., Bardgett, R. D., Wall, D. H. \& Garey, J. R. Molecular study of worldwide distribution and diversity of soil animals. Proc. Natl Acad. Sci. USA 108, 17720-17725 (2011).

167. Robeson, M. S. et al. Soil rotifer communities are extremely diverse globally but spatially autocorrelated locally. Proc. Natl Acad. Sci. USA 108, 4406-4410 (2011).

168. Wall, D. H. et al. Global decomposition experiment shows soil animal impacts on decomposition are climate-dependent. Glob. Chang. Biol. 14, 2661-2677 (2008).

169. Pachl, P. et al. The tropics as an ancient cradle of oribatid mite diversity. Acarologia 57, 309-322 (2016).

170. Dahlsjö, C. A. L. et al. First comparison of quantitative estimates of termite biomass and abundance reveals strong intercontinental differences. J. Trop. Ecol. 30, 143-152 (2014).

171. Briones, M. J. I., Ineson, P. \& Heinemeyer, A. Predicting potential impacts of climate change on the geographical distribution of enchytraeids: a metaanalysis approach. Glob. Chang. Biol. 13, 2252-2269 (2007).

172. Silver, W. L. \& Miya, R. K. Global patterns in root decomposition: comparisons of climate and litter quality effects. Oecologia 129, 407-419 (2001).

173. Zhang, T. 'an, Chen, H. Y. H. \& Ruan, H. Global negative effects of nitrogen deposition on soil microbes. ISME J. 12, 1817-1825 (2018).

174. Sinsabaugh, R. L., Turner, B. L. \& Talbot, J. M. Stoichiometry of microbial carbon use efficiency in soils. Ecol. Monogr. 86, 172-189 (2016).

175. Xu, M. \& Shang, H. Contribution of soil respiration to the global carbon equation. J. Plant Physiol. 203, 16-28 (2016).

176. Raich, J. W. \& Tufekciogul, A. Vegetation and soil respiration: correlations and controls. Biogeochemistry 48, 71-90 (2000).
177. Wang, J., Chadwick, D. R., Cheng, Y. \& Yan, X. Global analysis of agricultural soil denitrification in response to fertilizer nitrogen. Sci. Total Environ. 616617, 908-917 (2018).

178. Rahmati, M. et al. Development and analysis of the Soil Water Infiltration Global database. Earth Syst. Sci. Data 10, 1237-1263 (2017).

179. Serna-Chavez, H. M., Fierer, N. \& van Bodegom, P. M. Global drivers and patterns of microbial abundance in soil: Global patterns of soil microbial biomass. Glob. Ecol. Biogeogr. 22, 1162-1172 (2013).

180. Howison, R. A., Olff, H., Koppel, J. \& Smit, C. Biotically driven vegetation mosaics in grazing ecosystems: the battle between bioturbation and biocompaction. Ecol. Monogr. 87, 363-378 (2017).

181. Lehmann, A., Zheng, W. \& Rillig, M. C. Soil biota contributions to soil aggregation. Nat. Ecol. Evol.1, 1-9 (2017).

182. Zomer, R. J., Trabucco, A., Bossio, D. A. \& Verchot, L. V. Climate change mitigation: a spatial analysis of global land suitability for clean development mechanism afforestation and reforestation. Agric. Ecosyst. Environ. 126, 67-80 (2008).

183. van Straaten Oliver, Z. R. T. A. \& Bossio, D. Carbon, Land And Water: A Global Analysis Of The Hydrologic Dimensions Of Climate Change Mitigation Through Afforestation/reforestation. (IWMI, 2006).

\section{Acknowledgements}

This manuscript developed from discussions within the German Centre of Integrative Biodiversity Research funded by the German Research Foundation (DFG FZT118). CAG and NE acknowledge funding by iDiv (DFG FZT118) Flexpool proposal 34600850. C.A. G., A.H.B., J.S., A.C., N.G.R., S.C., L.B., M.C.R., F.B., J.O., G.P., H.R.P.P., M.W., T.W., K. K., and N.E. acknowledge funding by iDiv (DFG FZT118) Flexpool proposal 34600844. N.E. acknowledges funding by the DFG (FOR 1451) and the European Research Council (ERC) under the European Union's Horizon 2020 research and innovation programme (grant agreement no. 677232). Finally we would like to acknowledge the contribution of all the authors that provided their datasets for analysis within this paper. Open access funding provided by Projekt DEAL.

\section{Author contributions}

C.A.G., A.H.B., J.S., A.C., N.G.R., S.C., L.B., M.C.R., F.B., J.O., G.P., H.R.P.P., M.W. T.W., K.K., F.T.M., B.S., and N.E. conceived and designed the study; C.A.G., A.H.B., J.S., A.C., N.G.R., S.C., L.B., M.C.R., F.B., J.O., G.P., H.R.P.P., M.W., T.W., K.K., F.T.M., E.C., C.M., A.O., D.H.W., M.D.B., R.B., D.C., T.G., B.S., and N.E. contributed to the data acquisition and all authors had substantial contributions to the interpretation of the data, writing, and review of the final manuscript.

\section{Competing interests}

The authors declare no competing interests.

\section{Additional information}

Supplementary information is available for this paper at https://doi.org/10.1038/s41467020-17688-2.

Correspondence and requests for materials should be addressed to C.A.G.

Peer review information Nature Communications thanks Thibaud Decaëns, Thiago Rangel and the other, anonymous, reviewer for their contribution to the peer review of this work. Peer reviewer reports are available.

Reprints and permission information is available at http://www.nature.com/reprints

Publisher's note Springer Nature remains neutral with regard to jurisdictional claims in published maps and institutional affiliations.

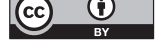

Open Access This article is licensed under a Creative Commons Attribution 4.0 International License, which permits use, sharing, adaptation, distribution and reproduction in any medium or format, as long as you give appropriate credit to the original author(s) and the source, provide a link to the Creative Commons license, and indicate if changes were made. The images or other third party material in this article are included in the article's Creative Commons license, unless indicated otherwise in a credit line to the material. If material is not included in the article's Creative Commons license and your intended use is not permitted by statutory regulation or exceeds the permitted use, you will need to obtain permission directly from the copyright holder. To view a copy of this license, visit http://creativecommons.org/ licenses/by/4.0/.

(C) The Author(s) 2020 